\title{
Glyme-based electrolytes for lithium metal batteries using insertion electrodes:
}

\section{an electrochemical study}

Shuangying $\mathrm{Wei}^{1}$, Zhenguang $\mathrm{Li}^{2}$, Kento Kimura ${ }^{2}$, Shoichi Inoue ${ }^{2}$, Loris Pandini ${ }^{1}$, Daniele Di Lecce $^{1}$, Yoichi Tominaga ${ }^{2,3^{*}}$ and Jusef Hassoun ${ }^{1,3,4^{*}}$

${ }^{1}$ University of Ferrara, Department of Chemical and Pharmaceutical Sciences, Via Fossato di Mortara 17, 44121, Ferrara, Italy.

2 Tokyo University of Agriculture and Technology, Graduate School of Bio-Applications and Systems Engineering (BASE), 2-24-16, Naka-cho, Koganei-shi, Tokyo 184-8588, Japan.

${ }^{3}$ Institute of Global Innovation Research (GIR), Tokyo University of Agriculture and Technology (TUAT), Tokyo, Japan

${ }^{4}$ National Interuniversity Consortium of Materials Science and Technology (INSTM) University of Ferrara Research Unit, University of Ferrara, Via Fossato di Mortara, 17, 44121, Ferrara, Italy.

Corresponding Authors: jusef.hassoun@unife.it, ytominag@cc.tuat.ac.jp

\section{Abstract}

We report an electrochemical study of end-capped glymes dissolving lithium salts as electrolyte solutions for lithium metal batteries. Various electrolyte formulations including triethylene and diethylene glycol dimethyl ethers as solvents and lithium salts employing bis(fluorosulfonyl)imide $\left(\mathrm{FSI}^{-}\right)$, bis(trifluoromethanesulfonyl)imide $\left(\mathrm{TFSI}^{-}\right)$, and bis(pentafluoroethanesulfonyl)imide $\left(\mathrm{BETI}^{-}\right)$anions are explored. The ions transport properties, the lithium/electrolyte interphase characteristics and the electrochemical stability window are investigated by means of chronoamperometry, electrochemical impedance spectroscopy, galvanostatic cycling, and voltammetry measurements. The comparative study suggests electrochemical properties well suitable for lithium battery application which enable long cycling. The electrolyte solutions are investigated in cells using an insertion cathode material, i.e., lithium iron phosphate $\left(\mathrm{LiFePO}_{4}\right)$, and the high-energy lithium metal anode. The results reveal the electrolyte composition has a remarkable effect on the cell performances, and indicate the solutions of LiTFSI salt in either in 
diglyme and in triglyme as the most adequate formulations for possible applications among the ones herein investigated.

\section{Keywords}

Glyme electrolyte; LiTFSI; LiFSI; LiBETI; Lithium metal/Lithium iron phosphate

\section{Introduction}

Lithium-ion batteries are currently the most employed energy storage systems for portable electronic devices and electric vehicles due to intriguing characteristics in terms of energy density, efficiency, and reliability, and are now considered as a suitable technology for grid applications ranging up to tens of $\mathrm{MWh}$ [1]. Extensive researches by academy and industry have effectively improved the lithium-ion batteries since first commercialization and fast spread in the early nineties, thus leading to high-performance cell configurations able to ensure up to $250 \mathrm{Wh} \mathrm{kg}^{-1}[2,3]$, satisfactory safety level and long cycle life [4]. Furthermore, a renewed interest has been recently devoted towards the high-energy lithium metal anode [5-10], which has high theoretical specific capacity $\left(3860 \mathrm{mAh} \mathrm{g}^{-1}\right)$, low density $\left(0.59 \mathrm{~g} \mathrm{~cm}^{-3}\right)$, and the lowest electrochemical potential (-3.040 V vs standard hydrogen electrode) [11]. Lithium metal cells have been limited mainly to the primary configuration so far, except for a few examples of rechargeable cells, owing to possible growth of lithium dendrites upon cycling and low stripping/plating efficiency [12,13]. However, secondary lithium metal batteries might ensure higher gravimetric and volumetric energy density than the lithium-ion ones by properly addressing the metal electrodeposition and safety issues [11]. Accordingly, lithium cells using transition metal oxide cathode are able to deliver about $440 \mathrm{Wh}$ $\mathrm{kg}^{-1}$ [13]. Recently, increasing attention has been paid to rechargeable metal cells using sulfur [14] and oxygen [15] cathodes, which might achieve even higher energy density values [16].

The optimization of suitable electrolyte solutions plays crucial role for mitigating the issues affecting the lithium metal anode and allowing reversible electrodeposition processes and low risks of thermal runaways [17]. Therefore, the use of polymer or solid-state inorganic electrolytes, such 
as poly(ethylene oxide) (PEO) [18], polyethylene carbonate (PEC) [19] or glass LISICON and NASICON [20], has been investigated to prevent lithium dendrites growth and exothermic reactions associated with possible short circuit. On the other hand, liquid electrolytes having low flammability with respect to conventional carbonate-based solutions, e.g., ionic liquids [4,21] and glymes [22,23] dissolving lithium salts, might ensure at the same time satisfactory $\mathrm{Li}^{+}$transport properties at room temperature, wide electrochemical stability window, and suitable safety content.

Poly(ethylene glycol) dimethyl ethers with small $n$ number in $\mathrm{R}_{1} \mathrm{O}\left(\mathrm{CH}_{2} \mathrm{CH}_{2}\right)_{n} \mathrm{R}_{2}$, i.e., the end-capped glymes, are liquid oligomers suitable as aprotic solvents for lithium batteries electrolytes, and are receiving a great deal of attention in view of their compatibility with the highenergy $\mathrm{C} / \mathrm{O}_{2}$ and sulfur cathodes [23-25]. Lately, the appealing characteristics of this class of solvents for lithium-metal batteries using conventional insertion cathodes has been demonstrated [26-28]. Indeed, glyme-based electrolytes are typically lowly flammable with respect to the standard carbonate-based electrolytes, while exhibit slightly lower performances in terms of conductivity and cation transference number [22,23]. In particular, their physical-chemical and electrochemical features may be favorably tuned by changing the ether chain length [23]. Thus, high-molecular-weight glymes ensure higher thermal stability and wider electrochemical stability window, although they have higher viscosity and higher freezing point [23]. Therefore, different solutions might be suitable for diverse applications, ranging from low-temperature devices, highenergy cells based on whether insertion or conversion cathodes and lithium-metal anode, as well as safe battery packs with low risk of thermal runaway.

Accordingly, we have lately investigated in several reports the characteristics of electrolyte formulations comprising glymes with various chin length that dissolve either lithium trifluoromethanesulfonate $\left(\mathrm{LiCF}_{3} \mathrm{SO}_{3}\right)$ or lithium bis(trifluoromethanesulfonyl)imide (LiTFSI) for application in lithium cell with insertion cathode materials $[22,26,28,29]$. The results suggested that the electrode/electrolyte interphase stability of $\mathrm{Li} / \mathrm{LiFePO}_{4}$ cells using a pristine glyme-based solution with $\mathrm{LiCF}_{3} \mathrm{SO}_{3}$ salt may be actually improved by adding lithium nitrate $\left(\mathrm{LiNO}_{3}\right)$, that is, a 
film forming sacrificial additive widely employed to ensure long cycle life of $\mathrm{Li} / \mathrm{S}$ cells $[22,26,29,30]$. Furthermore, the studies revealed an important role of the electrolyte nature and composition in determining its characteristics; however further studies are needed to fully elucidate the effect of the electrolyte formulation in terms of $-\left(\mathrm{OCH}_{2} \mathrm{CH}_{2}\right)-$ chain length and lithium salt chemistry. Following this trend, we investigate herein the electrochemical properties of glymebased solutions of various lithium salts as electrolyte for $\mathrm{Li} / \mathrm{LiFePO}_{4}$ cells. Diethylene glycol dimethyl ether $\left(\left(\mathrm{CH}_{3} \mathrm{OCH}_{2} \mathrm{CH}_{2}\right)_{2} \mathrm{O}\right.$, DEGDME) and triethylene glycol dimethyl ether $\left(\mathrm{CH}_{3}\left(\mathrm{OCH}_{2} \mathrm{CH}_{2}\right)_{3} \mathrm{OCH}_{3}\right.$, TREGDME) are selected as suitable solvents to achieve low viscosity, hence higher conductivity with respect to long-chain glymes [23,29,31], while either lithium bis(fluorosulfonyl)imide (LiFSI), or lithium bis(trifluoromethanesulfonyl)imide (LiTFSI), or lithium bis(perfluoroethanesulfonyl)imide (LiBETI) are chosen as lithium salts [32,33]. A comparative electrochemical study is carried out on the six solutions by using voltammetry, impedance spectroscopy, chronoamperometry, and galvanostatic techniques, in order to shed light on the effect of the electrolyte formulation on the ionic conductivity, the lithium transference number, the electrochemical stability window, as well as the lithium/electrolyte interphase characteristics under static and dynamic conditions. Therefore, we evaluate the possible use of the glyme-based solutions in lithium cells with $\mathrm{LiFePO}_{4}$ insertion cathode. Our results may be of definite interest to develop suitable electrolytes for rechargeable batteries using the high-energy lithium metal anode.

\section{Experimental}

Six electrolyte solutions were prepared in Ar-filled glovebox (MBraun, $\mathrm{O}_{2}$ and $\mathrm{H}_{2} \mathrm{O}$ content below 1 ppm) by dissolving either lithium bis(fluorosulfonyl)imide (LiFSI, Sigma-Aldrich), lithium bis(trifluoromethanesulfonyl)imide $\quad$ (LiTFSI, $\quad$ Sigma-Aldrich), $\quad$ or $\quad$ lithium bis(perfluoroethanesulfonyl)imide (LiBETI, Sigma-Aldrich) in either diethylene glycol dimethyl ether (DEGDME, Sigma-Aldrich) or triethylene glycol dimethyl ether (TREGDME, Sigma- 
Aldrich) solvents with a concentration of $1 \mathrm{~mol}$ of salt in $1 \mathrm{~kg}$ of solvent $\left(1 \mathrm{~mol} \mathrm{~kg}^{-1}\right)$. Prior to electrolyte preparation, the salts were dried under vacuum at $110{ }^{\circ} \mathrm{C}$ for $24 \mathrm{~h}$, while the solvents were dried under molecular sieves (5 A, Sigma-Aldrich) until the water content was below 10 ppm, as determined by 899 Karl Fischer Coulometer, Metrohm. The electrolyte solutions are indicated below by the acronyms listed in Table 1 .

\section{Table 1}

An electrode slurry was prepared by mixing $\mathrm{LiFePO}_{4}$ (LFP) powder [34], polymer binder (PVDF 6020, Solvay), and conductive carbon (Super P, Timcal) in 1-methyl-2-pyrrolidinone (NMP, anhydrous, Sigma-Aldrich), using the weight proportion of 80:10:10. The slurry was cast through doctor blade on an aluminum foil (thickness of $15 \mu \mathrm{m}$, MTI Corporation), which was then dried for $3 \mathrm{~h}$ on a hot plate at $70{ }^{\circ} \mathrm{C}$, cut into the form of $14 \mathrm{~mm}$ disks, and dried overnight at 110 ${ }^{\circ} \mathrm{C}$ under vacuum. The final active material loading over the electrode foil was about $5.4 \mathrm{mg} \mathrm{cm}^{-2}$. Carbon electrodes coated on either aluminum (thickness of $15 \mu \mathrm{m}$, MTI Corporation) or copper (thickness of $25 \mu \mathrm{m}$, MTI Corporation) were also prepared by doctor blade casting of Super P carbon (Timcal) and PVdF 6020 (Solvay) with weight ratio of 80:20; the electrodes were cut into 10 mm disks and dried overnight at $110{ }^{\circ} \mathrm{C}$ under vacuum.

The ionic conductivity was studied by electrochemical impedance spectroscopy (EIS) within temperature ranging from $20^{\circ} \mathrm{C}$ to $80{ }^{\circ} \mathrm{C}$, using symmetric stainless steel/electrolyte/stainless steel CR2032 coin-cells (MTI) equipped with a Teflon separator in order to fix the thickness. The EIS was performed within the $500 \mathrm{kHz}-10 \mathrm{~Hz}$ frequency range by applying an alternate signal with amplitude of $10 \mathrm{mV}$ through a VersaSTAT MC Princeton Applied Research (PAR) potentiostat.

CR2032 coin-cells (MTI Corporation) and three-electrodes T-type cells were assembled in an Ar-filled glovebox (MBraun, $\mathrm{O}_{2}$ and $\mathrm{H}_{2} \mathrm{O}$ content below $1 \mathrm{ppm}$ ), by using lithium metal disks as counter and reference electrodes, and a Whatman ${ }^{\circledR}$ GF/D glass fiber separator soaked by the electrolyte solution. Electrodes having diameter of 14 and $10 \mathrm{~mm}$ were employed for preparing coin-cells and T-type cells, respectively. 
The lithium transference number $\left(t^{+}\right)$of the electrolyte solutions was calculated by means of the electrochemical method [35] proposed by Evans et al. Chronoamperometry and EIS measurements were performed on two-electrode $\mathrm{Li} / \mathrm{Li}$ symmetrical T-type cell using 10 Whatman ${ }^{\circledR}$ GF/D glass fiber separators through a VersaSTAT MC Princeton Applied Research (PAR, AMETEK) potentiostat. The increase of cell thickness due to the large number of separators leads to higher electrolyte resistance with respect to standard cells using one separator. This condition favors the application of the method proposed by Evans et al. [35], which allows the determination of $t^{+}$from a steady-state condition where the current flow is mainly controlled by the cation transport into the electrolyte bulk, thus limiting perturbations due to passivating layers at the electrode/electrolyte interphase. EIS was carried out before and after the chronoamperometry by applying an alternate voltage signal with amplitude of $10 \mathrm{mV}$ in frequency range from $500 \mathrm{kHz}$ to $100 \mathrm{mHz}$. Chronoamperometry was performed by applying to the cells a voltage of $30 \mathrm{mV}$ for $90 \mathrm{~min}$. The data acquisition at the polarization start (close to time 0) and upon the first 300 seconds was performed by recording 1 point each $0.05 \mathrm{~s}$ and the maximum current $\left(\mathrm{I}_{0}\right)$ was obtained at the time $0.05 \mathrm{~s}$ after starting. The data acquisition near by the steady state upon polarization was performed by recording 1 point each $10 \mathrm{~s}$ and the minimum current $\left(\mathrm{I}_{\mathrm{ss}}\right)$ was obtained after $90 \mathrm{~min}$. The initial and steady-state resistances were determined through nonlinear least squares (NLLS) fit of the impedance spectra by Boukamp package [36,37]. The transference numbers have been measured at least three times taking carefully the very first current values as $I_{0}$. The estimated errors on current and resistance were lower than $1 \%$ and $5 \%$, and the chi-square was lower than $10^{-4}$. Accordingly, the estimated error associated with $\mathrm{t}^{+}$is $10 \%$. Further information is summarized in Tables $\mathrm{S} 1$ and $\mathrm{S} 2$ of the supplementary data. In spite of the relatively low error on $\mathrm{t}^{+}$, possible further deviation due to intrinsic instability of the SEI during the measurement leading to increase of the electrode/electrolyte interface resistance cannot be excluded. The electrochemical stability window of the electrolyte solutions was evaluated by voltammetry measurements at a scan rate of $0.1 \mathrm{mV}$ $\mathrm{s}^{-1}$ in T-type cells through a VersaSTAT MC Princeton Applied Research (PAR, AMETEK) 
potentiostat. The high-potential range was studied through linear sweep voltammetry (LSV) by using carbon coated on aluminum as the working electrode; the stability to reduction was studied through cyclic voltammetry $(\mathrm{CV})$ within $0.01-2 \mathrm{~V} v s$. $\mathrm{Li}^{+} / \mathrm{Li}$ by using carbon coated copper as the working electrode.

The characteristics of the Li/electrolyte interphase were investigated by coupling EIS and galvanostatic cycling measurements on symmetrical $\mathrm{Li} / \mathrm{Li}$ coin-cells, performed through VersaSTAT MC Princeton Applied Research (PAR, AMETEK) potentiostat and a MACCOR Series 4000 battery test system, respectively. The Li/electrolyte interphase resistance was evaluated by EIS measurements upon cell storage by applying an alternate voltage signal with amplitude of 10 $\mathrm{mV}$ in frequency range from $500 \mathrm{kHz}$ to $1 \mathrm{~Hz}$. The spectra were analyzed by NLLS method through Boukamp package [36,37]. Lithium stripping/deposition galvanostatic measurements were performed by using a current density of $0.1 \mathrm{~mA} \mathrm{~cm}^{-2}$ and a step time of $1 \mathrm{~h}$.

The electrolyte solutions were studied in $\mathrm{Li} / \mathrm{LiFePO}_{4}$ cells by galvanostatic cycling through a MACCOR Series 4000 battery test system. The charge/discharge measurements were performed at a $\mathrm{C} / 3$ rate $\left(1 \mathrm{C}=170 \mathrm{~mA} \mathrm{~g}^{-1}\right)$ within the $2.8-3.9 \mathrm{~V}$ voltage range.

\section{Result and Discussion}

A suitable electrolyte solution for lithium metal battery application should ensure fast ion transport to achieve high current density [38]. In this respect, the electrolyte formulation in terms of ether chain extension and lithium salt composition may play a crucial role by determining viscosity, ion solvation ability, and ion association degree, i.e., parameters that strongly affect ionic conductivity and lithium transference number $[23,29,39]$. Herein, we have investigated for all the solutions the ionic conductivity by EIS within the temperature range from about 20 to about $80{ }^{\circ} \mathrm{C}$ (Figure 1 ) and the lithium transference number $\left(t^{+}\right)$by the electrochemical method [35] proposed by Evans et al. (Figure 2). Figure 1 reveals the expected remarkable effect of the glyme chain length on the ionic

conductivity [23], with values of the order of $10^{-2} \mathrm{~S} \mathrm{~cm}^{-1}$ for the DEGDME-based solutions (panel 
a) and $10^{-3} \mathrm{~S} \mathrm{~cm}^{-1}$ for the TREGDME-based ones (panel b), which are generally considered suitable for battery application [23]. As for the lithium salt composition, EIS suggests that the anion size controls the charge mobility within DEGDME-based electrolyte solutions, most likely due to effects of the anion charge density on the solvation shell characteristics $[40,41]$. Thus, the ionic conductivity of DEGDME-based solutions increases as the anion size increases from LiFSI, to LiTFSI and to LiBETI (see Figure 1a). On the other hand, TREGDME-based electrolytes do not exhibit the same trend, while they have ionic conductivity barely depending on the salt composition (see Figure 1b). This observation may suggest a complex effect of chain length on the ion solvation ability [42] which may be further investigated by using different techniques than electrochemistry, that is, a study in progress in our laboratories for future reports.

\section{Figure 1}

The high conductivity values estimated by EIS are expected to allow low polarization at high current density. However, it is worth mentioning that conductivity is referred to the overall charge transference, while the actual current in a lithium cell is driven by the net $\mathrm{Li}^{+}$flow, that is, by the lithium transference number $t^{+}$[9]. The $t^{+}$number shown in Figure 2 at room temperature represents the fraction of charge carried by lithium ions through the electrolyte solutions. This parameter has been determined by performing EIS and chronoamperometry measurements on symmetrical lithium cells, as described in the experimental section. Figure S1 in the Supplementary data shows the chronoamperometry profiles and the Nyquist plots of the impedance spectra for all the samples. The transference number for the cation $\left(t^{+}\right)$is given by equation 1 [35]:

$$
t^{+}=\frac{I_{S S}\left(\Delta V-I_{0} R_{0}\right)}{I_{0}\left(\Delta V-I_{S S} R_{S S}\right)}
$$

where $\Delta V$ is the applied potential, $I_{0}$ is the initial current, $I_{S S}$ is the steady-state current, while $R_{0}$ and $R_{S S}$ are the lithium/electrolyte interphase resistances before and after the polarization, respectively. The measurements indicate a raise of lithium transference number by increasing the chain length from DEGDME (Figure 2a) to TREGDME (Figure 2b), due to a stronger solvation of the relatively 
big anions promoted by a longer glyme with respect to a shorter one which decreases anion mobility compared to the easily solvated small lithium ions. Meanwhile, increasing anion size actually reduces its mobility and consequently leads to the raise of the lithium transference number from LiTFSI and LiFSI, which exhibit comparable values, to LiBETI (panels a and b of Figure 2). These observations further suggest that the relative size of anion and glyme can control the solvation characteristics, thus leading to significant effects on conductivity and $\mathrm{Li}^{+}$transport [40-42]. $\mathrm{The}^{+}{ }^{+}$ motion into the electrolyte has been studied both by electrochemical techniques [43] and by NMR including solution of various salts in glyme [23]. In particular, our NMR previous studies indicated that the transport number may depend both on the solvent-salt combination [23] and on the temperature, as the activation energy for diffusion of $\mathrm{Li}^{+}$and anion may differ $[31,44]$. Furthermore, electrochemical methods typically lead to higher $\mathrm{t}^{+}$number than NMR by measuring the net alkali ion motion upon application of electric field, while the latter technique takes into account the selfdiffusion coefficients of the ion species [45]. Therefore, we have performed an additional test at $50^{\circ} \mathrm{C}$ instead of $50^{\circ} \mathrm{C}$, and reported the results in Figure S1 in the Supplementary, while the corresponding $\mathrm{Li}^{+}$transference numbers are represented in Figure 2. The data reveal a general decrease of the lithium transference number by the increasing the temperature as likely due to the increase of anions and solvent molecules motion into the electrolyte, and to enhanced solvation which hinder the transport of the lithium ions as observed in previous paper [42]. Hence, the transference numbers drop from values of about $0.5-0.8$, depending on the electrolyte solution, to a values of about $0.3-0.4$ (for further details see Table S1, Table S2, Figure S1, Figure S1, and corresponding discussion in Supplementary data).

\section{Figure 2}

A remarkable effect of the electrolyte composition on the electrochemical stability window is observed in Figure 3 in which voltammetry experiments are performed in lithium cells employing carbon coated on metal foils (either $\mathrm{Cu}$ or $\mathrm{Al}$ ) which reasonably reproduces the electrode configuration used in battery, usually formed by active material, conductive carbon, and polymer 
binder. Accordingly, the measurements are expected to provide useful information on the actual parasitic electrochemical reactions over the electrodes surface, which may be underestimated in the case of cell using bare Ni or Pt foils as the working electrodes. Panels a and c of Figure 3 show that the solutions employing LiBETI have the highest oxidative stability (up to $4.6 \mathrm{~V} v s$. $\mathrm{Li}^{+} / \mathrm{Li}$ ), which suggests possible application with cathodes that have working voltage above $4.0 \mathrm{~V} v s . \mathrm{Li}^{+} / \mathrm{Li}$ $[22,46,47]$, while solutions using LiFSI reveal the lowest one (about 4.1-4.2 V vs. $\mathrm{Li}^{+} / \mathrm{Li}$ ). Intermediate values of the stability to oxidation are observed for solutions using LiTFSI (about 4.24.4 $\mathrm{V} v s . \mathrm{Li}^{+} / \mathrm{Li}$ ). On the other hand, the raise of the chain length from DEGDME (Figure 3a) to TREGDME (Figure 3c) hardly affects the oxidative stability of solutions using LiBETI salt, increases the one of solutions using LiFSI from about 4.1 to about $4.2 \mathrm{~V} v s$. $\mathrm{Li}^{+} / \mathrm{Li}$, and decreases the one of solutions using LiTFSI from about 4.4 to about $4.2 \mathrm{~V} v s . \mathrm{Li}^{+} / \mathrm{Li}$, thereby revealing a slight effect of the increasing of chain length from 2 to 3 ether groups, depending on the chemical nature of the dissolved salt [23]. It is worth mentioning that all the electrolyte solutions exhibit stability to oxidation suitable for application with $\mathrm{LiFePO}_{4}$ olivine insertion cathode, which operates at about $3.5 \mathrm{~V}$ vs. $\mathrm{Li}^{+} / \mathrm{Li}$ [48]. The low-potential range is surveyed in panels $\mathrm{b}$ and $\mathrm{d}$ of Figure 3, which report the CV profiles for the DEGDME-based and TREGDME-based electrolytes, respectively. The first reduction scan in Figure $3 \mathrm{~b}$ reveals formation of the solid electrolyte interphase (SEI) over the carbon electrode coated on copper below 1.1, and at about 0.4 and $0.6 \mathrm{~V}$ vs. $\mathrm{Li}^{+} / \mathrm{Li}$ for DEGDME dissolving LiFSI, LiFTSI and LiBETI, respectively [49]. The subsequent cycles display for all the DEGDME-based electrolytes reversible electrochemical processes ranging between 1.4 and $0 \mathrm{~V}$ vs. $\mathrm{Li}^{+} / \mathrm{Li}$, which may be attributed to $\mathrm{Li}^{+}$insertion/deinsertion within the carbon material and to possible lithium plating/stripping [31]. The TREGDME-based electrolytes show a similar voltammetry response in the low-potential range (Figure 3d), with SEI formation over carbon around 1.3, 0.6 and $0.7 \mathrm{~V}$ vs. $\mathrm{Li}^{+} / \mathrm{Li}$ upon the first reduction scan [49] for LiFSI, LiFTSI and LiBETI, respectively, and reversible lithium insertion and plating below $1.4 \mathrm{~V} v s$. $\mathrm{Li}^{+} / \mathrm{Li}$ [31]. Therefore, we may state that all the electrolytes show suitable stability to reduction 
characterized by the absence of parasitic reactions after the first cycle, which is characterized by a SEI formation at potential depending on the chemical nature of the dissolved lithium salt, with particular focus on LiFSI which has the highest value, that is, above $1 \mathrm{~V} v s$. $\mathrm{Li}^{+} / \mathrm{Li}$.

\section{Figure 3}

The stability window of the studied electrolytes extends from 0 to above $4 \mathrm{~V} v s . \mathrm{Li}^{+} / \mathrm{Li}$, which is a proper range for application in lithium battery using insertion olivine cathodes [22]. However, the stability towards the lithium metal anode, besides the potential window, is a crucial requirement for ensuring reversible electrodeposition with limited dendrite formation and, accordingly, proper cell operation. Herein, we have investigated the electrochemical characteristics of the lithium/electrolyte interphase under static and dynamic conditions by coupling EIS and galvanostatic cycling measurements. Figure 4 shows the lithium/electrolyte interphase resistance trend upon 30 days of storage of symmetrical lithium cell as determined by NLLS analysis of impedance spectra [36,37], while Figure S3 in the Supplementary data reports the corresponding Nyquist plots, detailed for cells using DEGDME (Figure S3a,c,e) and TREGDME (Figure S3b,d,f). It is noteworthy that we have employed the same equivalent circuit (i.e., $R_{e}\left(R_{i} Q_{i}\right) Q_{g}$, see the Supplementary data) in which $R_{e}$ is the electrolyte resistance and $R_{i}$ is the electrode/electrolyte interphase resistance for all the impedance tests on $\mathrm{Li} / \mathrm{Li}$ symmetrical cell. Accordingly, the comparison of Figs. S1 and S2 reveals a significant difference in $\mathrm{R}_{\mathrm{e}}$ between the cells used for the lithium transference number evaluation and the aging tests, that is, a much higher electrolyte resistance for the T-cells of Fig. S1 compared to the coin-cells of Fig. S2. Such a difference is attributed to the higher thickness of the T-cells used for measuring $t^{+}$(see the experimental section for further details about cell preparation and experimental setup).

Figure 4a reveals for the DEGDME-based solutions interphase resistance values increasing during the first day of aging to about $300 \Omega$ for LiFSI, $150 \Omega$ for LiTFSI and $720 \Omega$ for LiBETI. The resistance further rises to $500 \Omega$ after 6 days for DEGDME-LiFSI and to $830 \Omega$ after 4 days for DEGDME-LiBETI, while then gradually decreases to about 300 and $350 \Omega$, respectively, upon 30 
days of cell storage, according to SEI dissolution and consolidation phenomena [50]. On the other hand, the DEGDME-LiTFSI solution exhibits lower interphase resistance characterized by a rather constant trend upon aging, with maximum values below $230 \Omega$. Fig. $4 \mathrm{~b}$ reveals different trends of $\mathrm{R}_{\mathrm{i}}$ for the solutions using TREGDME upon the $1^{\text {st }}$ day of aging, which depends on the lithium salt. Thus, the electrode/electrolyte interphase resistance increases during the $1^{\text {st }}$ day from about 110 and $200 \Omega$ to 190 and $390 \Omega$ for TREGDME-LiFSI and TREGDME-LiBETI, respectively, while decreases from about 230 to $180 \Omega$ for TREGDME-LiTFSI. Afterwards all the TREGDME-based solutions exhibit a fluctuation of the lithium/electrolyte interphase resistance around $300 \Omega$, thus suggesting stabilization of the SEI upon 30 days [50]. Growth, dissolution and consolidation of the SEI over the lithium metal electrode, as well as gradual change of the composition, are typically observed in lithium cells and may lead to significant change of the cell impedance [51]. Such phenomena may be certainly affected by the electrolyte composition as well as by the amount of solution in the cell and salt concentration. Indeed, these parameters strongly affect the SEI composition and morphology in terms of nature and distribution of inorganic and organic species [51].

Figure 4 clearly shows lower resistance values and excellent stability over time towards lithium metal for the DEGDME-LiTFSI, TREGDME-LiFSI and TREGDME-LiTFSI compositions compared to the other formulations, thus suggesting these electrolytes as the most suitable for application in lithium metal batteries based on glyme containing either LiFSI or LiTFSI [23].

\section{Figure 4}

Figure 5 shows the voltage profiles of lithium stripping/deposition tests performed by galvanostatic cycling of symmetrical lithium cells for the electrolytes using DEGDME (panel a) and TREGDME (panel b). These tests may reveal the features of the lithium/electrolyte interphase upon the electrodeposition process throughout 10 days of repeated cycling, and indirectly provide evidence of the cell resistance trend during operation by taking into account the lithium stripping/deposition overvoltage, that is, the cell polarization. Indeed, Li/DEGDME-LiBETI/Li and 
Li/DEGDME-LiFSI/Li cells show a gradual increase of polarization during the first day from about $60 \mathrm{mV}$ to about $90 \mathrm{mV}$, while the polarization of the Li/DEGDME-LiTFSI/Li cell increases from about $30 \mathrm{mV}$ to about $40 \mathrm{mV}$ due to the SEI modification by the electrochemical process (Figure 5a). Subsequently, the overvoltage of the Li/DEGDME-LiBETI/Li cell slightly decreases to $80 \mathrm{mV}$ and remains rather stable by 10 days of cycling, while the DEGDME-LiFSI and DEGDME-LiTFSI solutions exhibit a reduction of the cell polarization to values lower than $30 \mathrm{mV}$ upon cycling, likely due to the already observed partial SEI dissolution and consolidation phenomena [50]. The data of Figure 5a indicate that the cycling test leads to the formation of very stable and lowly resistive SEI film for DEGDME solutions using LiTFSI, and of remarkably resistive SEI film for solutions using LiBETI and LiFSI. Interestingly, the resistance of the cell using DEGDME-LiBETI solution remains stably high by cycling, while the one of the cell using DEGDME-LiFSI solution gradually decreases reaching a value similar to the one ascribed to DEGDME-LiTFSI. The change from DEGDME to TREGDME solvent significantly modifies both the trend and the steady state values of cell polarization (Figure 5b). Indeed, the cell using TREGDME-LiBETI shows an initial polarization of about $30 \mathrm{mV}$ slightly increasing and stabilizing by 10 days of cycling to about 45 $\mathrm{mV}$, which are remarkably lower values compared to DEGDME-LiBETI. Analogously, the cell using TREGDME-LiFSI reveals lower initial polarization with respect to DEGDME-LiFSI, with value decreasing from about $30 \mathrm{mV}$ to about $15 \mathrm{mV}$ by cycling, while TREGDME-LiTFSI electrolyte shows during the early stages higher initial polarization value (about $90 \mathrm{mV}$ ) compared to DEGDME-LiTFSI, which rapidly decreases by few cycles and stabilizes to about $35 \mathrm{mV}$. Beside the initial resistance changes owing to growth, partial dissolution and consolidation of the SEI [50], Figure 5 suggests LiTFSI and LiFSI as the most performing salts in terms of low polarization of lithium stripping/deposition process, and TREGDME as the preferred solvent, which is in line with the resistance evolution already observed in Figure 4. Furthermore, the data of Figure 5 demonstrate a compatibility with lithium metal and cycling trend depending on the adopted electrolyte formulation. 


\section{Figure 5}

In order to further characterize the stability of the Li/electrolyte interphase we have performed an additional measurement which combines the two tests of Figure 4 and 5. Accordingly, we have performed a galvanostatic lithium stripping/deposition cycling test in $\mathrm{Li} / \mathrm{Li}$ symmetrical cells and repeated it after a period of rest of $24 \mathrm{~h}$ and collected electrochemical impedance spectroscopy before and after each test. Figure 6 reports the voltage profiles of the stripping/deposition tests and the Nyquist plots of the EIS before the test $\left(\mathrm{P}_{1}\right)$, after 5 cycles $\left(\mathrm{P}_{2}\right)$, upon $24 \mathrm{~h}$ or rest after above cycling $\left(\mathrm{P}_{3}\right)$, and after additional 5 cycles $\left(\mathrm{P}_{4}\right)$ using the various electrolytes. Very interestingly, the measurements indicate a rather good Li/electrolyte interphase, with low values of stripping/deposition polarization (limited to values below $20 \mathrm{mV}$ ) stable or slightly decreasing by the ongoing of cycles, and slightly changing resistances values upon time, even after the rest period adopted in the work in line with the findings of Figure 4 and Figure 5. Therefore, this measurement further suggests the suitability of the electrolyte studied herein for lithium battery. Additionally, we have performed lithium stripping/deposition cyclic voltammetry tests of in $\mathrm{Li} / \mathrm{Cu}$ cells using the various solution herein studied as reported in Figure S4 (Supplementary data). The CVs clearly reveal a polarization and a stripping/deposition magnitude (current) strongly depending on the adopted salt/solvent combination. Furthermore, the graphs generally indicate a low polarization value ranging from about $0.05 \mathrm{~V}$ to $0.15 \mathrm{~V}$, thus further suggesting the suitability of the studied electrolyte for battery application.

\section{Figure 6}

In summary, the results of the tests in symmetrical Li/Li cells suggest a gradual decrease of the electrode/electrolyte interphase resistance over the lithium-metal electrode upon cycling for the solutions containing LiFSI and LiTFSI salts. Similar cell behavior has been already observed for electrolyte formulations based on alkyl carbonates and glymes, and ascribed to changes of composition and morphology of the SEI layer due to repeated lithium electro-deposition/dissolution $[29,31,52,53]$. Recent works have shown that cycling may affect thickness and $\mathrm{Li}^{+}$diffusivity of the 
passivation film, as well as increase the effective surface area of the lithium metal owing to possible increase of the electrode roughness, thereby leading to a drop of the cell impedance $[52,53]$. Both solutions using LiTFSI benefit from a favorable combination of good electrochemical properties, namely high conductivity and fast $\mathrm{Li}^{+}$diffusivity, wide electrochemical stability window, as well as the ability to form suitable and conductive SEI over the lithium metal electrode under both static and dynamic conditions. Accordingly, the LiTFSI-based electrolytes exhibit remarkable electrochemical performances among the studied compositions. On the other hand, the other formulations ensure suitable electrochemical behavior for application in lithium metal batteries, except for the DEGDME-LiBETI which shows poor performance. Various solution of LiTFSI and LiFSI in glymes have demonstrated good film forming ability and very promising results in lithium cells employing whether insertion electrodes, i.e., $\mathrm{LiFePO}_{4}$ and $\mathrm{LiNi}_{1 / 3} \mathrm{Mn}_{1 / 3} \mathrm{Co}_{1 / 3} \mathrm{O}_{2}$, or highcapacity conversion cathodes [54,55]. Furthermore, recent studies suggested enhanced cycling behavior of $\mathrm{Li} / \mathrm{LiFePO}_{4}$ cells employing concentrated solutions of cyclic and linear ethers with both LiFSI and LiFTFSI salts [56]. Accordingly, our results evidence comparable cell performances with the literature, and advantageously reveal the effect of the increase of glyme chain length and anion size on the electrochemical features.

Various Li/LFP cells employing the electrolyte solutions were assembled and comparatively studied by galvanostatic cycling at a $\mathrm{C} / 3$ rate $\left(1 \mathrm{C}=170 \mathrm{~mA} \mathrm{~g}^{-1}\right)$. Figure 7 displays the cycling behavior (panels a and c) and the voltage profiles (panels b and d) for DEGDME- and TREGMEbased electrolytes (Figure $7 \mathrm{a}-\mathrm{b}$ and $7 \mathrm{c}-\mathrm{d}$, respectively). The measurements reveal a remarkable effect of the electrolyte formulation on the lithium cell performances. The Li/DEGDMELiBETI/LFP cell delivers a reversible capacity approaching $130 \mathrm{mAh} \mathrm{g}^{-1}$ after initial activation likely due to wetting of cathode; however, the capacity drops to $0 \mathrm{mAh} \mathrm{g}^{-1}$ after few cycles (see Figure 7a) owing to a gradual cell polarization increase. Such a cell failure has been observed in several tests which have been carried out using the same cell configuration and experimental setup (data not shown), and may be reasonably related to the poor passivation properties and high 
resistance at the lithium/electrolyte interphase of the DEGDME-LiBETI solution, already observed by the tests of Figures $4 \mathrm{a}$ and 5a. The Li/DEGDME-LiFSI/LFP cell exhibits a comparable activation trend, and a steady-state capacity of $134 \mathrm{mAh} \mathrm{g}^{-1}$ without any decay upon 100 cycles. The Li/DEGDME-LiTFSI/LFP cell delivers an initial discharge capacity of $153 \mathrm{mAh} \mathrm{g}^{-1}$ and maintains a stable reversible capacity of $147 \mathrm{mAh} \mathrm{g}^{-1}$ after 100 cycles with capacity retention as high as $96.1 \%$ (Figure $7 \mathrm{a}$ ). Figure $7 \mathrm{~b}$ shows the related voltage profiles of the $5^{\text {th }}$ cycle of the various electrolytes. The cells exhibit the typical voltage plateau of LFP materials centered at about $3.45 \mathrm{~V}$ [48] with small polarization. The Li/DEGDME-LiTFSI/LFP cell shows the best performances in terms of reversible capacity, cycling stability and cell polarization among the three configurations (see panels a and b of Figure 7). Panels $\mathrm{c}$ and $\mathrm{d}$ of Figure 7 evidence a similar trend in terms of performances for the TREGDME-based solution, but suitable cycling behavior for the Li/TREGDME-LiBETI/LFP cell. The cells using TREGDME-LiBETI, TREGDME-LiFSI, and TREGDME-LiTFSI deliver steady-state capacities of 137,144 , and $151 \mathrm{mAh} \mathrm{g}^{-1}$, respectively, with negligible fading after 100 cycles (see Figure 7c). The Li/TREGDME-LiBETI/LFP and Li/TREGDME-LiTFSI/LFP cells exhibit at the $5^{\text {th }}$ cycle similar polarization of the process at about 3.45 V [48], as shown in Figure 7d, while the Li/TREGDME-LiFSI/LFP one has polarization as low as $7 \mathrm{mV}$, in agreement with the small overvoltage values associated with the lithium stripping/deposition at the anode side (see Figure 5b). It is worth noting that Fig. 6 suggest a difference in the wetting ability of the cathode by the electrolyte solution among the six composition herein investigated. The solutions using LiFSI are apparently more affected by the wetting than those using the large $\mathrm{BETI}^{-}$anion, since they show an activation process leading to a gradual increase of capacity upon cycling. On the other hand, the solution employing LiTFSI are apparently not affected by the electrode wettability. The cell activation herein shown is in agreement with recent reports on glyme-based electrolytes with LFP cathodes [29]; however, the observed trend by changing the electrolyte composition apparently may not be related with the expected increase of viscosity by increasing chain length and anion size, demonstrated in previous 
works [57,58]. A possible effect of the anion on cathode/electrolyte interphase might be investigated by coupling electrochemical and spectroscopy techniques in further works aiming at the cell performance optimization. However, minor effect of the cell assembling and electrode morphology on the magnitude of the observed activation trend cannot be excluded.

Therefore, both cells using LiTFSI show the most remarkable cycling performances, which may be ascribed to the high conductivity and favorable lithium passivation properties of the related electrolyte solution with low-molecular-weight glyme. The other formulations exhibit suitable electrochemical behavior for application in lithium metal batteries, except for the DEGDMELiBETI which shows very poor performances.

\section{Figure 7}

With this respect, previous studies on alkyl carbonate-based electrolytes conducted by combining pyrolysis, gas chromatography, and mass spectroscopy have evidenced that the anion nature certainly affects the chemical composition of the SEI layer over lithium metal [59]. Accordingly, the SEI is typically formed by various species ascribed to the decomposition of the anions, i.e., inorganic compounds such as $\mathrm{LiF}, \mathrm{LiOH}$ and $\mathrm{Li}_{2} \mathrm{CO}_{3}$, which may remarkably influence the lithium/electrolyte interphase resistance, as well as by inorganic and organic products mostly affected by the chemistry of the solvent. Thus, $\mathrm{Li}_{2} \mathrm{CO}_{3}$, lithium dicarbonates $\left(\left(\mathrm{ROCO}_{2} \mathrm{Li}\right)_{2}\right)$, and semicarbonates $\left(\mathrm{ROCO}_{2} \mathrm{Li}\right)$ are commonly observed in conventional carbonate-based solutions, while the use of ether-based electrolytes usually leads to formation of alkoxides (ROLi) [60]. Such an heterogenous composition of the passivation layer may have a significant impact on the morphology of both lithium and SEI by inducing heterogenous current distribution over the electrode surface and, thus, rough structures. This phenomenon has been evidenced in a comparative investigation of solutions of $\mathrm{LiPF}_{6}$, LiTFSI and LiBETI in propylene carbonate [61]. This work has suggested that LiBETI leads to smooth, thin and stable SEI, which might be reflected into low electrode/electrolyte interphase resistance and suitable cell performance. The expected change of SEI composition due the use of glymes instead of carbonates has possibly a detrimental 
effect on the electrolyte stability against lithium. With this respect, a recent study of several glymebased solutions has evidenced that the increase of ether chain length has major impact on the electrochemical features of the passivation layer formed over the lithium-metal electrode under both static and dynamic conditions [23].

\section{Conclusion}

Electrolyte solutions based on low-molecular-weight glymes may be efficiently employed in rechargeable batteries coupling insertion $\mathrm{LiFePO}_{4}$ olivine cathode and high-energy lithium metal anode. Our comparative study revealed that the electrolyte formulation in terms of lithium salt chemical nature and ether chain length plays a crucial role in determining suitable electrochemical features for ensuring remarkable cell performances. Thus, the decrease of chain length from triglyme to diglyme led to an increase of the ionic conductivity from about $10^{-3}$ to about $10^{-2} \mathrm{~S}$ $\mathrm{cm}^{-1}$, as revealed by EIS, and to a decrease of the lithium transference number determined by coupling EIS and chronoamperometry measurements. The electrochemical investigation suggested an effect of the anion size on the cation transference number, with values of about 0.8 for DEGDME-LiBETI and TREGDME-LiBETI, 0.7 for TREGDME-LiTFSI and TREGDME-LiFSI, and 0.5 for DEGDME-LiTFSI and DEGDME-LiFSI. All the electrolyte formulations were electrochemically stable within the potential range from 0 to above $4 \mathrm{~V} v s$. $\mathrm{Li}^{+} / \mathrm{Li}$, with decomposition starting at a potential as high as $4.6 \mathrm{~V}$ vs. $\mathrm{Li}^{+} / \mathrm{Li}$ when LiBETI was employed. However, the use of LiBETI affected the formation of a stable and low-resistance SEI over the lithium metal anode, particularly in DEGDME solvent. Accordingly, the Li/DEGDME$\mathrm{LiBETI}_{\mathrm{LiFePO}}$ cell showed very poor performance, while the $\mathrm{Li} / \mathrm{TREGDME}-\mathrm{LiBETI} / \mathrm{LiFePO}_{4}$ one exhibited suitable behavior but lower capacity than that of the other TREGDME-based cells. For example, the solutions of LiFSI in DEGDME and TREGDME had promising characteristics for application and formed suitable interphase with the lithium metal electrode, thereby leading to lithium cells with stable capacity ranging between 134 and $144 \mathrm{mAh} \mathrm{g}^{-1}$ upon 100 cycles at a C/3 
rate $\left(1 \mathrm{C}=170 \mathrm{~mA} \mathrm{~g}^{-1}\right)$. The LiTFSI-based electrolytes showed the best electrochemical performances in lithium metal cell with $\mathrm{LiFePO}_{4}$, with reversible capacity ranging from $147 \mathrm{mAh}$ $\mathrm{g}^{-1}$ to $153 \mathrm{mAh} \mathrm{g}^{-1}$ during 100 cycles at a $\mathrm{C} / 3$ rate $\left(1 \mathrm{C}=170 \mathrm{~mA} \mathrm{~g}{ }^{-1}\right)$. Therefore, our results demonstrated the suitable electrochemical characteristics of glyme-based solutions for lithium cells employing olivine cathodes and may be of interest for an efficient and safe use of the metal anode in high-energy batteries.

\section{Acknowledgments}

This work was founded by the grant "Fondo di Ateneo per la Ricerca Locale (FAR) 2017", University of Ferrara, and by the Institute of Global Innovation Research (GIR) in Tokyo University of Agriculture and Technology, and performed within the collaboration project "Accordo di Collaborazione Quadro 2015" between the University of Ferrara (Department of Chemical and Pharmaceutical Sciences) and the Sapienza University of Rome (Department of Chemistry).

\section{References}

[1] D. Larcher, J.-M. Tarascon, Towards greener and more sustainable batteries for electrical energy storage, U.S. Geological Survey, Nat. Chem. 7 (2014) 19-29. doi:10.1038/nchem.2085.

[2] D. Di Lecce, R. Verrelli, J. Hassoun, Lithium-ion batteries for sustainable energy storage: recent advances towards new cell configurations, Green Chem. 19 (2017) 3442-3467. doi:10.1039/C7GC01328K.

[3] P.G. Bruce, S.A. Freunberger, L.J. Hardwick, J.-M. Tarascon, $\mathrm{Li}-\mathrm{O}_{2}$ and $\mathrm{Li}-\mathrm{S}$ batteries with high energy storage, Nat. Mater. 11 (2012) 19-29. doi:10.1038/nmat3191.

[4] G.A. Elia, U. Ulissi, S. Jeong, S. Passerini, J. Hassoun, Exceptional long-life performance of lithium-ion batteries using ionic liquid-based electrolytes, Energy Environ. Sci. 9 (2016) 3210-3220. doi:10.1039/C6EE01295G. 
[5] J.H. Shin, W.A. Henderson, G.B. Appetecchi, F. Alessandrini, S. Passerini, Recent developments in the ENEA lithium metal battery project, Electrochim. Acta. 50 (2005) 3859-3865. doi:10.1016/j.electacta.2005.02.049.

[6] S. Chou, J. Wang, J. Sun, D. Wexler, M. Forsyth, H. Liu, D.R. MacFarlane, S. Dou, High Capacity, Safety, and Enhanced Cyclability of Lithium Metal Battery Using a $\mathrm{V}_{2} \mathrm{O}_{5}$ Nanomaterial Cathode and Room Temperature Ionic Liquid Electrolyte, Chem. Mater. 20 (2008) 7044-7051. doi:10.1021/cm801468q.

[7] S. Choudhury, R. Mangal, A. Agrawal, L.A. Archer, A highly reversible room-temperature lithium metal battery based on crosslinked hairy nanoparticles, Nat. Commun. 6 (2015) 1-9. doi:10.1038/ncomms10101.

[8] B. Zhu, Y. Jin, X. Hu, Q. Zheng, S. Zhang, Q. Wang, J. Zhu, Poly(dimethylsiloxane) Thin Film as a Stable Interfacial Layer for High-Performance Lithium-Metal Battery Anodes, Adv. Mater. 29 (2017) 2-7. doi:10.1002/adma.201603755.

[9] D. Di Lecce, V. Sharova, S. Jeong, A. Moretti, S. Passerini, A multiple electrolyte concept for lithium-metal batteries, Solid State Ionics. 316 (2018) 66-74. doi:10.1016/j.ssi.2017.12.012.

[10] D. Di Lecce, J. Hassoun, Lithium Metal Battery Using LiFe ${ }_{0.5} \mathrm{Mn}_{0.5} \mathrm{PO}_{4}$ Olivine Cathode and Pyrrolidinium-Based Ionic Liquid Electrolyte, ACS Omega. 3 (2018) 8583-8588. doi:10.1021/acsomega.8b01328.

[11] W. Xu, J. Wang, F. Ding, X. Chen, E. Nasybulin, Y. Zhang, J.-G. Zhang, Lithium metal anodes for rechargeable batteries, Energy Environ. Sci. 7 (2014) 513-537. doi:10.1039/C3EE40795K.

[12] J. Qian, W.A. Henderson, W. Xu, P. Bhattacharya, M. Engelhard, O. Borodin, J.-G. Zhang, High rate and stable cycling of lithium metal anode, Nat. Commun. 6 (2015) 6362. doi:10.1038/ncomms7362.

[13] D. Lin, Y. Liu, Y. Cui, Reviving the lithium metal anode for high-energy batteries, Nat. 
Nanotechnol. 12 (2017) 194-206. doi:10.1038/nnano.2017.16.

[14] Q. Pang, X. Liang, C.Y. Kwok, L.F. Nazar, Advances in lithium-sulfur batteries based on multifunctional cathodes and electrolytes, Nat. Energy. 1 (2016) 16132. doi:10.1038/nenergy.2016.132.

[15] D. Aurbach, B.D. McCloskey, L.F. Nazar, P.G. Bruce, Advances in understanding mechanisms underpinning lithium-air batteries, Nat. Energy. 1 (2016) 16128. doi:10.1038/nenergy.2016.128.

[16] L. Carbone, S.G. Greenbaum, J. Hassoun, Lithium sulfur and lithium oxygen batteries: new frontiers of sustainable energy storage, Sustain. Energy Fuels. 1 (2017) 228-247. doi:10.1039/C6SE00124F.

[17] K. Zhang, G.H. Lee, M. Park, W. Li, Y.M. Kang, Recent Developments of the Lithium Metal Anode for Rechargeable Non-Aqueous Batteries, Adv. Energy Mater. 6 (2016) 1-14. doi:10.1002/aenm.201600811.

[18] G.B. Appetecchi, J. Hassoun, B. Scrosati, F. Croce, F. Cassel, M. Salomon, PEO-based electrolyte membranes II . All solid-state $\mathrm{Li} / \mathrm{LiFePO}_{4}$ polymer batteries, 124 (2003) 246-253. doi:10.1016/S0378-7753(03)00611-6.

[19] K. Kimura, H. Matsumoto, J. Hassoun, S. Panero, B. Scrosati, Y. Tominaga, A QuaternaryPoly(ethylene carbonate)-Lithium Bis(trifluoromethanesulfonyl)imide-Ionic Liquid-Silica Fiber Composite Polymer Electrolyte for Lithium Batteries, Electrochim. Acta. 175 (2015) 134-140. doi:10.1016/j.electacta.2015.03.117.

[20] T. Yamada, S. Ito, R. Omoda, T. Watanabe, Y. Aihara, M. Agostini, U. Ulissi, J. Hassoun, B. Scrosati, All Solid-State Lithium-Sulfur Battery Using a Glass-Type $\mathrm{P}_{2} \mathrm{~S}_{5}-\mathrm{Li}_{2} \mathrm{~S}$ Electrolyte: Benefits on Anode Kinetics, J. Electrochem. Soc. 162 (2015) A646-A651. doi:10.1149/2.0441504jes.

[21] C. Arbizzani, G. Gabrielli, M. Mastragostino, Thermal stability and flammability of electrolytes for lithium-ion batteries, J. Power Sources. 196 (2011) 4801-4805. 
doi:10.1016/j.jpowsour.2011.01.068.

[22] D. Di Lecce, L. Carbone, V. Gancitano, J. Hassoun, Rechargeable lithium battery using nonflammable electrolyte based on tetraethylene glycol dimethyl ether and olivine cathodes, J. Power Sources. 334 (2016) 146-153. doi:10.1016/j.jpowsour.2016.09.164.

[23] L. Carbone, M. Gobet, J. Peng, M. Devany, B. Scrosati, S. Greenbaum, J. Hassoun, Comparative Study of Ether-Based Electrolytes for Application in Lithium-Sulfur Battery, ACS Appl. Mater. Interfaces. 7 (2015) 13859-13865. doi:10.1021/acsami.5b02160.

[24] L. Carbone, P.T. Moro, M. Gobet, S. Munoz, M. Devany, S.G. Greenbaum, J. Hassoun, Enhanced Lithium Oxygen Battery Using a Glyme Electrolyte and Carbon Nanotubes, ACS Appl. Mater. Interfaces. 10 (2018) 16367-16375. doi:10.1021/acsami.7b19544.

[25] H.-G. Jung, J. Hassoun, J.-B. Park, Y.-K. Sun, B. Scrosati, An improved high-performance lithium-air battery, Nat. Chem. 4 (2012) 579-585. doi:10.1038/nchem.1376.

[26] L. Carbone, M. Gobet, J. Peng, M. Devany, B. Scrosati, S. Greenbaum, J. Hassoun, Polyethylene glycol dimethyl ether (PEGDME)-based electrolyte for lithium metal battery, J. Power Sources. 299 (2015) 460-464. doi:10.1016/j.jpowsour.2015.08.090.

[27] D.J. Lee, J. Hassoun, S. Panero, Y.K. Sun, B. Scrosati, A tetraethylene glycol dimethyletherlithium bis(oxalate)borate (TEGDME-LiBOB) electrolyte for advanced lithium ion batteries, Electrochem. Commun. 14 (2012) 43-46. doi:10.1016/j.elecom.2011.10.027.

[28] R. Bernhard, A. Latini, S. Panero, B. Scrosati, J. Hassoun, Poly(ethylenglycol)dimethylether-lithium bis(trifluoromethanesulfonyl)imide, PEG500DME-LiTFSI, as high viscosity electrolyte for lithium ion batteries, J. Power Sources. 226 (2013) 329-333. doi:10.1016/j.jpowsour.2012.10.059.

[29] L. Carbone, D. Di Lecce, M. Gobet, S. Munoz, M. Devany, S. Greenbaum, J. Hassoun, Relevant Features of a Triethylene Glycol Dimethyl Ether-Based Electrolyte for Application in Lithium Battery, ACS Appl. Mater. Interfaces. 9 (2017) 17085-17095. doi:10.1021/acsami.7b03235. 
[30] S. Xiong, K. Xie, Y. Diao, X. Hong, Properties of surface film on lithium anode with $\mathrm{LiNO}_{3}$ as lithium salt in electrolyte solution for lithium-sulfur batteries, Electrochim. Acta. 83 (2012) 78-86. doi:10.1016/j.electacta.2012.07.118.

[31] L. Carbone, T. Coneglian, M. Gobet, S. Munoz, M. Devany, S. Greenbaum, J. Hassoun, A simple approach for making a viable, safe, and high-performances lithium-sulfur battery, J. Power Sources. 377 (2018) 26-35. doi:10.1016/j.jpowsour.2017.11.079.

[32] K. Ueno, K. Yoshida, M. Tsuchiya, N. Tachikawa, K. Dokko, M. Watanabe, Glyme-lithium salt equimolar molten mixtures: Concentrated solutions or solvate ionic liquids?, J. Phys. Chem. B. 116 (2012) 11323-11331. doi:10.1021/jp307378j.

[33] W.A. Henderson, F. McKenna, M.A. Khan, N.R. Brooks, V.G. Young, R. Frech, Glymelithium bis(trifluoromethanesulfonyl)imide and glyme-lithium bis(perfluoroethanesulfonyl)imide phase behavior and solvate structures, Chem. Mater. 17 (2005) 2284-2289. doi:10.1021/cm047881j.

[34] S. Brutti, J. Hassoun, B. Scrosati, C.-Y.Y. Lin, H. Wu, H.-W.W. Hsieh, A high power SnC/C-LiFePO 4 lithium ion battery, J. Power Sources. 217 (2012) 72-76. doi:10.1016/j.jpowsour.2012.05.102.

[35] J. Evans, C. A. Vincent, P.G. Bruce, Electrochemical measurement of transference numbers in polymer electrolytes, Polymer. 28 (1987) 2324-2328. doi:10.1016/0032-3861(87)90394-6.

[36] B.A. Boukamp, A Nonlinear Least Squares Fit procedure for analysis of immittance data of electrochemical systems, Solid State Ionics. 20 (1986) 31-44. doi:10.1016/0167$2738(86) 90031-7$.

[37] B. Boukamp, A package for impedance/admittance data analysis, Solid State Ionics. 18-19 (1986) 136-140. doi:10.1016/0167-2738(86)90100-1.

[38] K. Xu, Electrolytes and Interphases in Li-Ion Batteries and Beyond, Chem. Rev. 114 (2014) 11503-11618. doi:10.1021/cr500003w.

[39] L. Carbone, J. Peng, M. Agostini, M. Gobet, M. Devany, B. Scrosati, S. Greenbaum, J. 
Hassoun, Carbon Composites for a High-Energy Lithium-Sulfur Battey with a Glyme-Based Electrolyte, ChemElectroChem. 4 (2017) 209-215. doi:10.1002/celc.201600586.

[40] S.H. Lapidus, N.N. Rajput, X. Qu, K.W. Chapman, K.A. Persson, P.J. Chupas, Solvation structure and energetics of electrolytes for multivalent energy storage, Phys. Chem. Chem. Phys. 16 (2014) 21941-21945. doi:10.1039/C4CP03015J.

[41] J. Wahlers, K.D. Fulfer, D.P. Harding, D.G. Kuroda, R. Kumar, R. Jorn, Solvation Structure and Concentration in Glyme-Based Sodium Electrolytes: A Combined Spectroscopic and Computational Study, J. Phys. Chem. C. 120 (2016) 17949-17959. doi:10.1021/acs.jpcc.6b06160.

[42] J. Peng, L. Carbone, M. Gobet, J. Hassoun, M. Devany, S. Greenbaum, Natural Abundance Oxygen-17 NMR Investigation of Lithium Ion Solvation in Glyme-based Electrolytes, Electrochim. Acta. 213 (2016) 606-612. doi:10.1016/j.electacta.2016.07.144.

[43] G.A. Elia, J. Park, Y. Sun, B. Scrosati, J. Hassoun, Role of the Lithium Salt in the Performance of Lithium-Oxygen Batteries: A Comparative Study, ChemElectroChem. 1 (2014) 47-50. doi:10.1002/celc.201300160.

[44] A. Johansson, A. Gogoll, J. Tegenfeldt, Diffusion and ionic conductivity in $\mathrm{Li}\left(\mathrm{CF}_{3} \mathrm{SO}_{3}\right) \mathrm{PEG}_{10}$ and $\mathrm{LiN}\left(\mathrm{CF}_{3} \mathrm{SO}_{2}\right)_{2} \mathrm{PEG}_{10}$, Polymer. 37 (1996) 1387-1393. doi:10.1016/0032-3861(96)81136-0.

[45] D. Di Lecce, L. Minnetti, D. Polidoro, V. Marangon, J. Hassoun, Triglyme-based electrolyte for sodium-ion and sodium-sulfur batteries, Ionics. (2019). doi:10.1007/s11581-019-02878w.

[46] D. Di Lecce, T. Hu, J. Hassoun, Electrochemical features of $\mathrm{LiMnPO}_{4}$ olivine prepared by sol-gel pathway, J. Alloys Compd. 693 (2017) 730-737. doi:10.1016/j.jallcom.2016.09.193.

[47] D. Di Lecce, P. Andreotti, M. Boni, G. Gasparro, G. Rizzati, J.-Y. Hwang, Y.-K. Sun, J. Hassoun, Multiwalled Carbon Nanotubes Anode in Lithium-Ion Battery with $\mathrm{LiCoO}_{2}$, $\mathrm{Li}\left[\mathrm{Ni}_{1 / 3} \mathrm{Co}_{1 / 3} \mathrm{Mn}_{1 / 3}\right] \mathrm{O}_{2}$, and $\mathrm{LiFe}_{1 / 4} \mathrm{Mn}_{1 / 2} \mathrm{Co}_{1 / 4} \mathrm{PO}_{4}$ Cathodes, ACS Sustain. Chem. Eng. 6 
(2018) 3225-3232. doi:10.1021/acssuschemeng.7b03395.

[48] D. Di Lecce, J. Hassoun, Lithium Transport Properties in $\mathrm{LiMn}_{1-\alpha} \mathrm{Fe}_{\alpha} \mathrm{PO}_{4}$ Olivine Cathodes, J. Phys. Chem. C. 119 (2015) 20855-20863. doi:10.1021/acs.jpcc.5b06727.

[49] J. Heine, P. Hilbig, X. Qi, P. Niehoff, M. Winter, P. Bieker, Fluoroethylene Carbonate as Electrolyte Additive in Tetraethylene Glycol Dimethyl Ether Based Electrolytes for Application in Lithium Ion and Lithium Metal Batteries, J. Electrochem. Soc. 162 (2015) A1094-A1101. doi:10.1149/2.0011507jes.

[50] J. Vetter, P. Novák, M.R. Wagner, C. Veit, K.-C. Möller, J.O. Besenhard, M. Winter, M. Wohlfahrt-Mehrens, C. Vogler, A. Hammouche, Ageing mechanisms in lithium-ion batteries, J. Power Sources. 147 (2005) 269-281. doi:10.1016/j.jpowsour.2005.01.006.

[51] S.M. Wood, C. Fang, E.J. Dufek, S.C. Nagpure, S. V. Sazhin, B. Liaw, Y.S. Meng, Predicting Calendar Aging in Lithium Metal Secondary Batteries: The Impacts of Solid Electrolyte Interphase Composition and Stability, Adv. Energy Mater. 8 (2018) 1801427. doi:10.1002/aenm.201801427.

[52] G. Bieker, M. Winter, P. Bieker, Electrochemical in situ investigations of SEI and dendrite formation on the lithium metal anode, Phys. Chem. Chem. Phys. 17 (2015) 8670-8679. doi:10.1039/C4CP05865H.

[53] E. Markevich, G. Salitra, F. Chesneau, M. Schmidt, D. Aurbach, Very Stable Lithium Metal Stripping-Plating at a High Rate and High Areal Capacity in Fluoroethylene CarbonateBased Organic Electrolyte Solution, ACS Energy Lett. 2 (2017) 1321-1326. doi:10.1021/acsenergylett.7b00300.

[54] D. Shanmukaraj, S. Lois, S. Fantini, F. Malbosc, M. Armand, High Conductivity Solvates with Unsymmetrical Glymes as New Electrolytes, Chem. Mater. 30 (2018) 246-251. doi:10.1021/acs.chemmater.7b04270.

[55] D. Di Lecce, V. Marangon, A. Benítez, Á. Caballero, J. Morales, E. Rodríguez-Castellón, J. Hassoun, High capacity semi-liquid lithium sulfur cells with enhanced reversibility for 
application in new-generation energy storage systems, J. Power Sources. 412 (2019) 575585. doi:10.1016/j.jpowsour.2018.11.068.

[56] Q. Ma, Z. Fang, P. Liu, J. Ma, X. Qi, W. Feng, J. Nie, Y.-S. Hu, H. Li, X. Huang, L. Chen, Z. Zhou, Improved Cycling Stability of Lithium-Metal Anode with Concentrated Electrolytes Based on Lithium (Fluorosulfonyl)(trifluoromethanesulfonyl)imide, ChemElectroChem. 3 (2016) 531-536. doi:10.1002/celc.201500520.

[57] P.J. Carvalho, C.H.G. Fonseca, M.-L.C.J. Moita, Â.F.S. Santos, J.A.P. Coutinho, Thermophysical Properties of Glycols and Glymes, J. Chem. Eng. Data. 60 (2015) 37213737. doi:10.1021/acs.jced.5b00662.

[58] H.-B. Han, S.-S. Zhou, D.-J. Zhang, S.-W. Feng, L.-F. Li, K. Liu, W.-F. Feng, J. Nie, H. Li, X.-J. Huang, Lithium bis(fluorosulfonyl)imide (LiFSI) as conducting salt for nonaqueous liquid electrolytes for lithium-ion batteries: Physicochemical and electrochemical properties, J. Power Sources. 196 (2011) 3623-3632. doi:10.1016/j.jpowsour.2010.12.040.

[59] R. Mogi, M. Inaba, Y. Iriyama, T. Abe, Z. Ogumi, Study of the Decomposition of Propylene Carbonate on Lithium Metal Surface by Pyrolysis-Gas Chromatography-Mass Spectroscopy, Langmuir. 19 (2003) 814-821. doi:10.1021/la026299b.

[60] M. Gauthier, T.J. Carney, A. Grimaud, L. Giordano, N. Pour, H.-H. Chang, D.P. Fenning, S.F. Lux, O. Paschos, C. Bauer, F. Maglia, S. Lupart, P. Lamp, Y. Shao-Horn, ElectrodeElectrolyte Interface in Li-Ion Batteries: Current Understanding and New Insights, J. Phys. Chem. Lett. 6 (2015) 4653-4672. doi:10.1021/acs.jpclett.5b01727.

[61] K. Naoi, The Surface Film Formed on a Lithium Metal Electrode in a New Imide Electrolyte, Lithium Bis(perfluoroethylsulfonylimide) $\left.\left[\mathrm{LiN}\left(\mathrm{C}_{2} \mathrm{~F}_{5} \mathrm{SO}_{2}\right]\right)_{2}\right]$, J. Electrochem. Soc. 146 (1999) 462. doi:10.1149/1.1391629. 


\section{Table captions}

Table 1. List of solvents and salts used for preparing the electrolyte samples and corresponding acronyms.

\section{Figure captions}

Figure 1. Ionic conductivity of the (a) DEGDME-LiTFSI, DEGDME-LiFSI, DEGDME-LiBETI and (b) TREGDME-LiTFSI, TREGDME-LiFSI, TREGDME-LiBETI electrolyte solutions determined by EIS measurements within the $20-80{ }^{\circ} \mathrm{C}$ temperature range in symmetric blocking electrodes cell. Frequency range $500 \mathrm{kHz}-10 \mathrm{~Hz}$. Signal amplitude of $10 \mathrm{mV}$. See Table 1 for sample acronym.

Figure 2. Lithium transference number at $25^{\circ} \mathrm{C}$ and $50{ }^{\circ} \mathrm{C}$ as determined by electrochemical method [35] of the (a) DEGDME-LiTFSI, DEGDME-LiFSI, DEGDME-LiBETI and (b) TREGDME-LiTFSI, TREGDME-LiFSI, TREGDME-LiBETI electrolyte solutions at $25{ }^{\circ} \mathrm{C}$. The measurement consists of chronoamperometry performed on $\mathrm{Li} / \mathrm{Li}$ symmetrical cell by applying a voltage of $30 \mathrm{mV}$ for $90 \mathrm{~min}$, and EIS carried out before and after the chronoamperometry by an alternate voltage signal with amplitude of $10 \mathrm{mV}$ in frequency range from $500 \mathrm{kHz}$ to $100 \mathrm{mHz}$ (the related chronoamperometry profiles and Nyquist plots are reported in Figure S1 in the Supplementary data). See Table 1 for sample acronym.

Figure 3. Electrochemical stability window of the (a,b) DEGDME-LiTFSI, DEGDME-LiFSI, DEGDME-LiBETI and (c,d) TREGDME-LiTFSI, TREGDME-LiFSI, TREGDME-LiBETI electrolyte solutions determined by linear sweep voltammetry (LSV, high-potential region, panels a and c) and by cyclic voltammetry (CV, low-potential region, panels $\mathbf{b}$ and $\mathbf{d})$ in three-electrode lithium cells using carbon-coated working electrode. Scan rate: $0.1 \mathrm{mV} \mathrm{s}^{-1}$. Potential limits: OCV $5 \mathrm{~V} v$ s. $\mathrm{Li}^{+} / \mathrm{Li}(\mathrm{LSV}) ; 0.01-2 \mathrm{~V}$ vs. $\mathrm{Li}^{+} / \mathrm{Li}(\mathrm{CV})$. Temperature: $25^{\circ} \mathrm{C}$. See the Experimental section for details on the measurement and Table 1 for sample acronyms. 
Figure 4. Lithium/electrolyte interphase resistance for the (a) DEGDME-LiTFSI, DEGDME-LiFSI, DEGDME-LiBETI and (b) TREGDME-LiTFSI, TREGDME-LiFSI, TREGDME-LiBETI formulations in Li/Li symmetrical cells as calculated by NLLS analysis of EIS data during 30 days of aging at $25^{\circ} \mathrm{C}$. EIS performed by applying an alternate voltage signal with amplitude of $10 \mathrm{mV}$ within the frequency range from $500 \mathrm{kHz}$ to $1 \mathrm{~Hz}$ (the related Nyquist plots are reported in Figure S3 in the Supplementary data). See Table 1 for sample acronym.

Figure 5. Voltage profiles of Li/Li symmetrical cells employing (a) DEGDME-LiTFSI, DEGDMELiFSI, DEGDME-LiBETI and (b) TREGDME-LiTFSI, TREGDME-LiFSI, TREGDME-LiBETI electrolyte solutions, cycled at a constant current density of $0.1 \mathrm{~mA} \mathrm{~cm}^{-2}$. Step time: $1 \mathrm{~h}$. Temperature $25^{\circ} \mathrm{C}$. See Table 1 for sample acronym.

Figure 6. Voltage profiles of lithium stripping/deposition galvanostatic cycling tests of in symmetrical Li/Li cells and corresponding Nyquist plots of the EIS before the test $\left(\mathrm{P}_{1}\right)$, after 5 cycles $\left(\mathrm{P}_{2}\right)$, upon $24 \mathrm{~h}$ or rest after above cycling $\left(\mathrm{P}_{3}\right)$, and after additional 5 cycles $\left(\mathrm{P}_{4}\right)$ using (a) DEGDME-LiTFSI, (b) TREGDMELiTFSI, (c) DEGDME-LiFSI, (d) TREGDME-LiFSI, (e) DEGDME-LiBETI, and (f) TREGDME-LiBETI (see Table 1 in the Experimental section of the manuscript for sample acronyms). Cycling test at a constant current density of $0.1 \mathrm{~mA} \mathrm{~cm}^{-2}$. Step time: 1h. EIS carried out by an AC signal with amplitude of $10 \mathrm{mV}$ in frequency range from $500 \mathrm{kHz}$ to $100 \mathrm{mHz}$. Temperature $25^{\circ} \mathrm{C}$.

Figure 7. Galvanostatic cycling at a $\mathrm{C} / 3$ rate $\left(1 \mathrm{C}=170 \mathrm{mAh} \mathrm{g}^{-1}\right)$ of $\mathrm{Li} / \mathrm{LiFePO}_{4}$ cells using (a,b) DEGDME-LiTFSI, DEGDME-LiFSI, DEGDME-LiBETI and (c,d) TREGDME-LiTFSI, TREGDME-LiFSI, TREGDME-LiBETI electrolyte solutions in terms of cycling behavior (panels a and $\mathbf{c}$ ) and of voltage profiles of the $5^{\text {th }}$ cycle (panels $\mathbf{b}$ and $\mathbf{d}$ ). Voltage range: $2.8-3.9 \mathrm{~V}$. Temperature $25^{\circ} \mathrm{C}$. See Table 1 for sample acronym. 


\section{Tables}

Table 1. List of solvents and salts used for preparing the electrolyte samples and corresponding acronyms.

\begin{tabular}{|c|c|c|}
\hline Solvent & Salt & Acronym \\
\hline $\begin{array}{l}\text { Diethylene glycol dimethyl ether } \\
\text { (DEGDME) }\end{array}$ & LiTFSI & DEGDME-LiTFSI \\
\hline $\begin{array}{l}\text { Diethylene glycol dimethyl ether } \\
\text { (DEGDME) }\end{array}$ & LiFSI & GDME-LiFSI \\
\hline $\begin{array}{l}\text { Diethylene glycol dimethyl ether } \\
\text { (DEGDME) }\end{array}$ & LiBETI & $\mathrm{I}$ \\
\hline $\begin{array}{l}\text { Triethylene glycol dimethyl ether } \\
\text { (TREGDME) }\end{array}$ & LiTFSI & TREGDME-LiTFSI \\
\hline $\begin{array}{l}\text { Triethylene glycol dimethyl ether } \\
\text { (TREGDME) }\end{array}$ & LiFSI & TREGDME-LiFSI \\
\hline $\begin{array}{l}\text { Triethylene glycol dimethyl ether } \\
\text { (TREGDME) }\end{array}$ & LiBETI & TREGDME-LiBETI \\
\hline
\end{tabular}



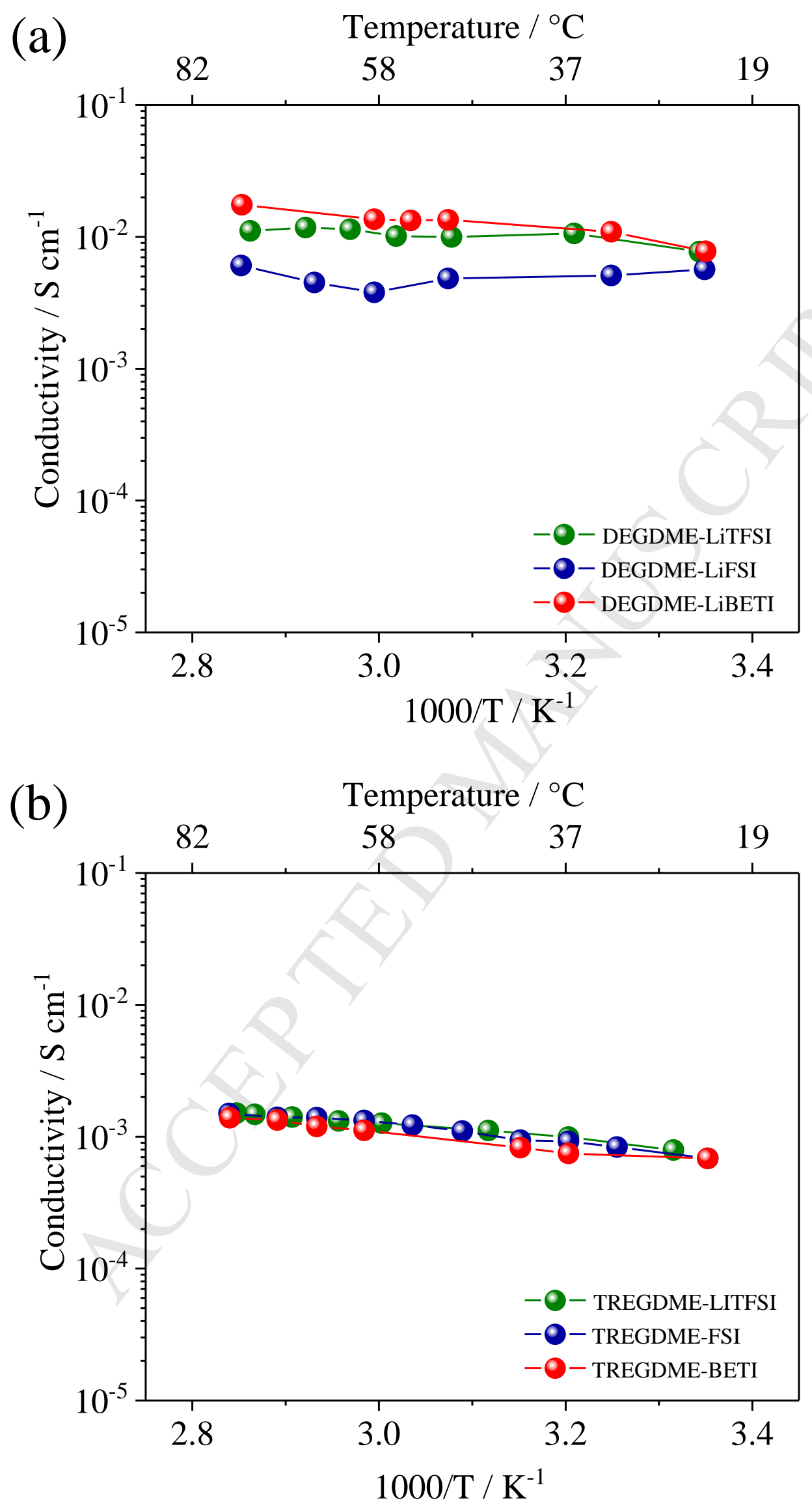

Figure 1 


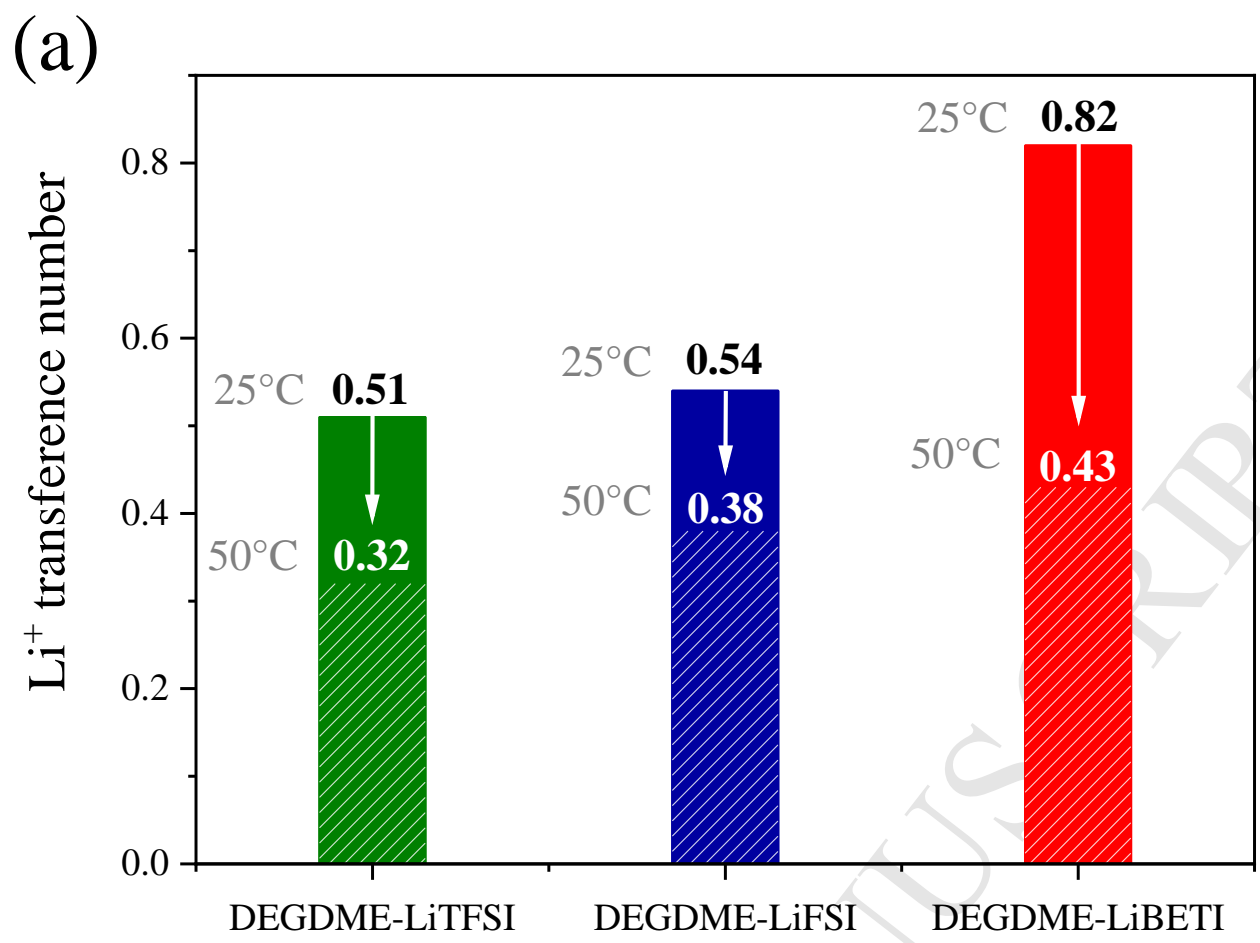

Electrolyte solution

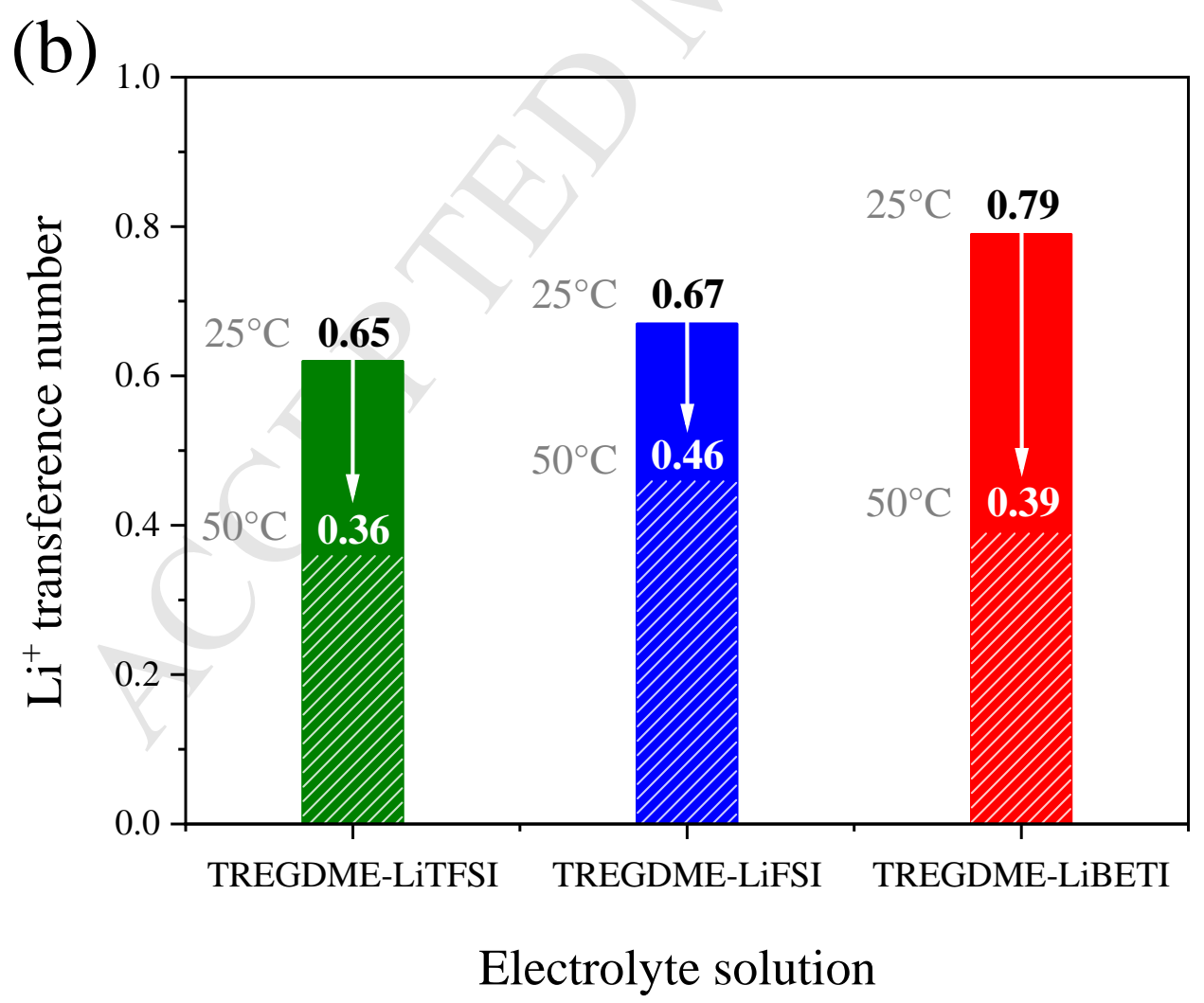

Figure 2 

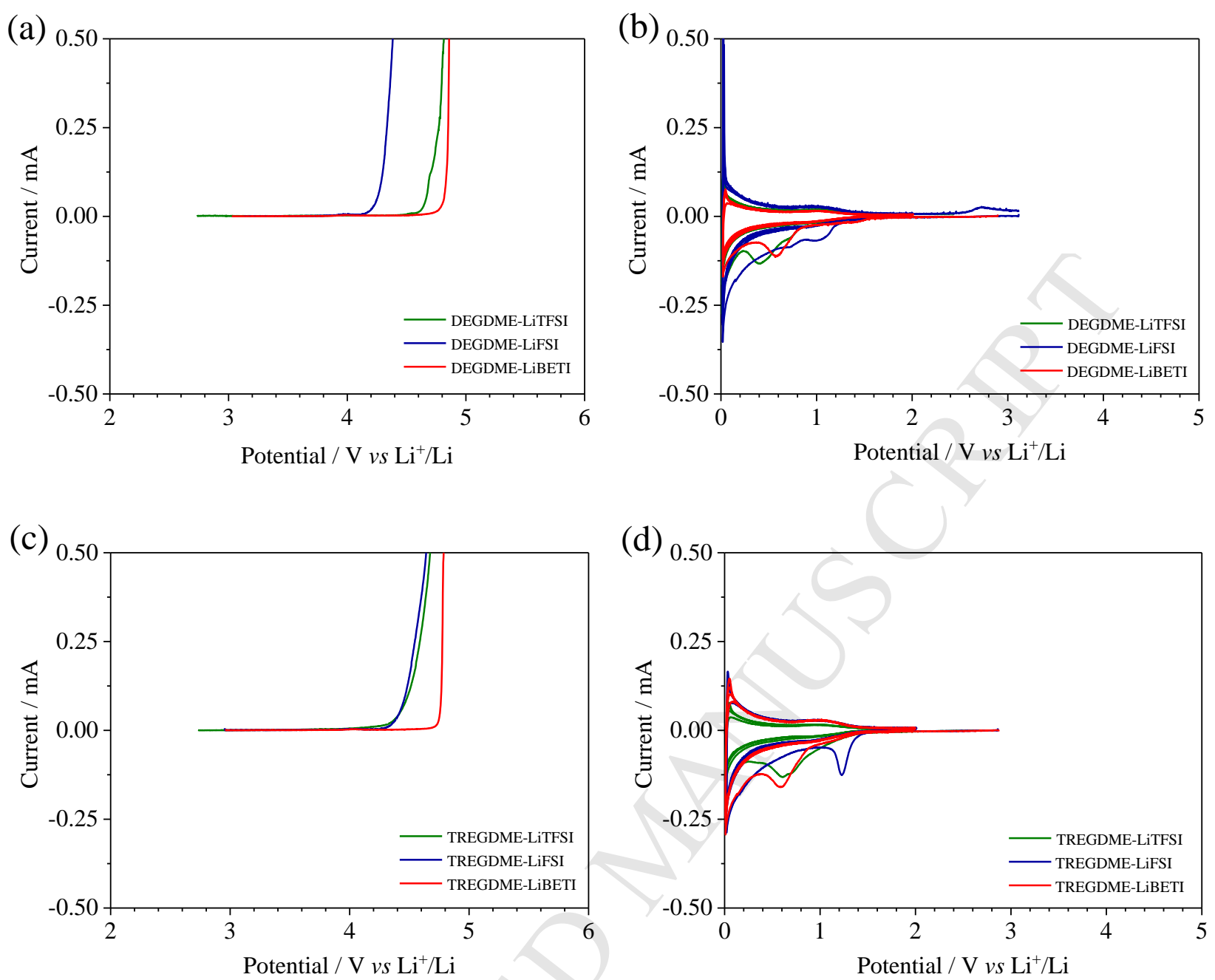

Figure 3 

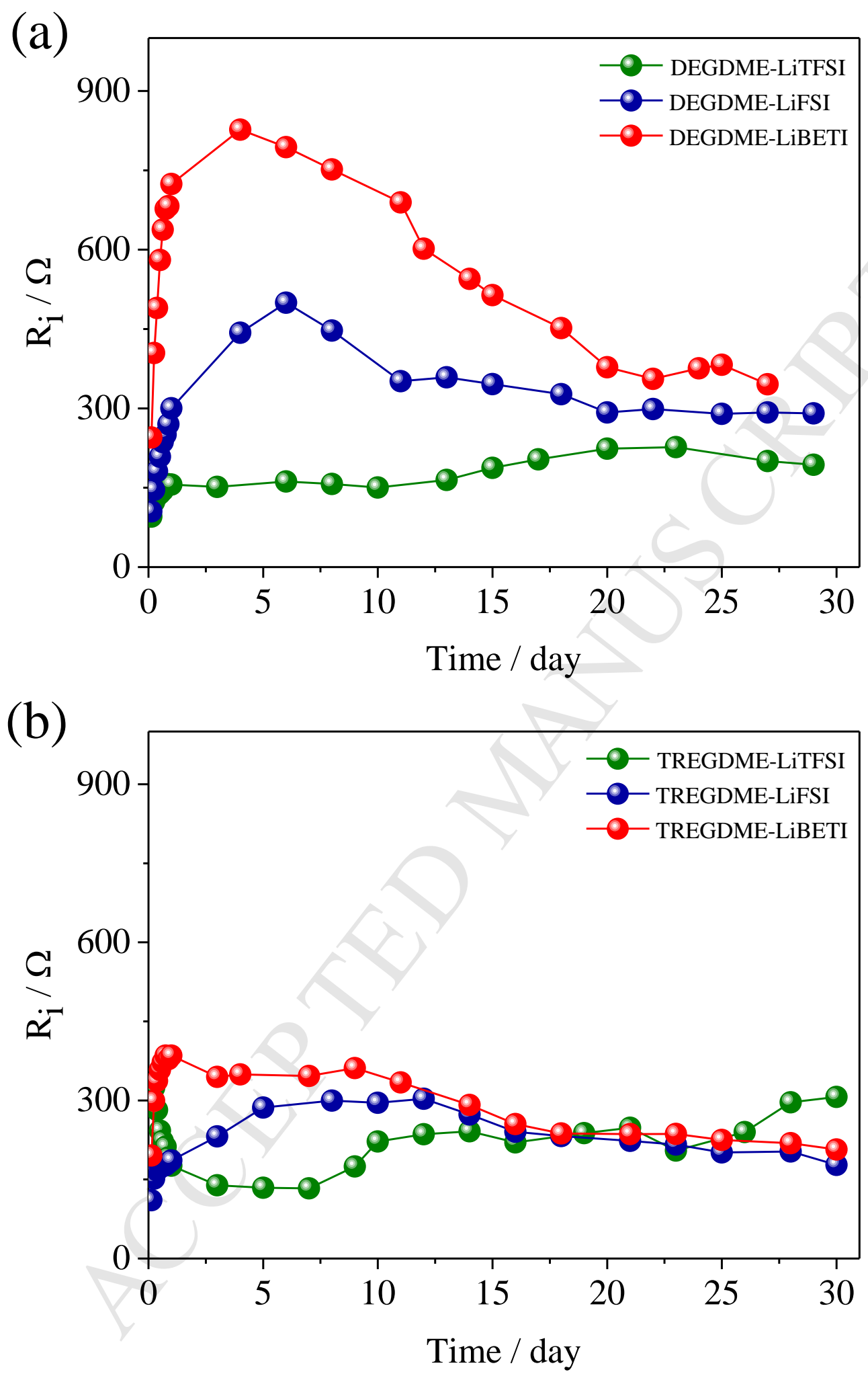

Figure 4 

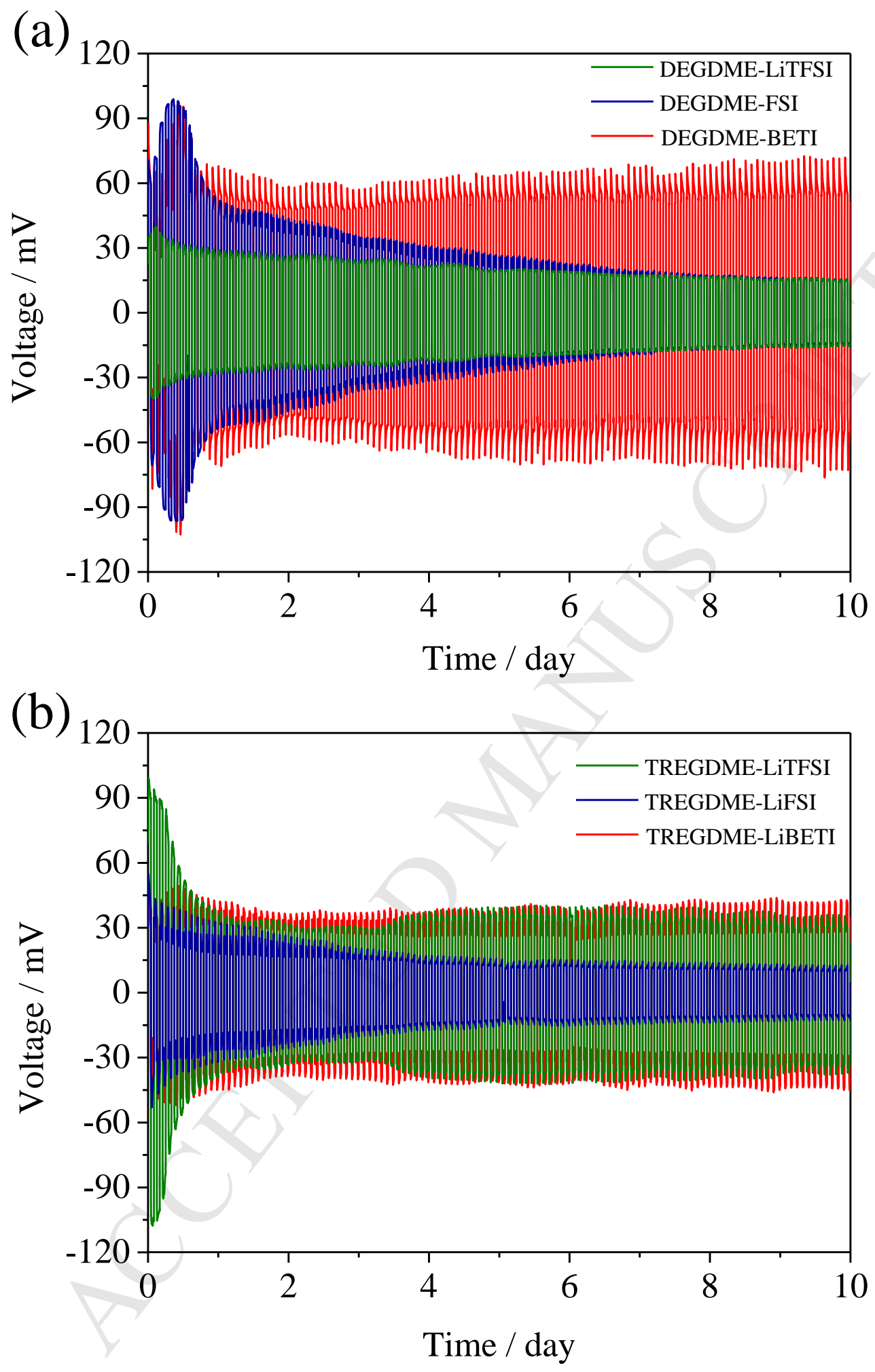

Figure 5 

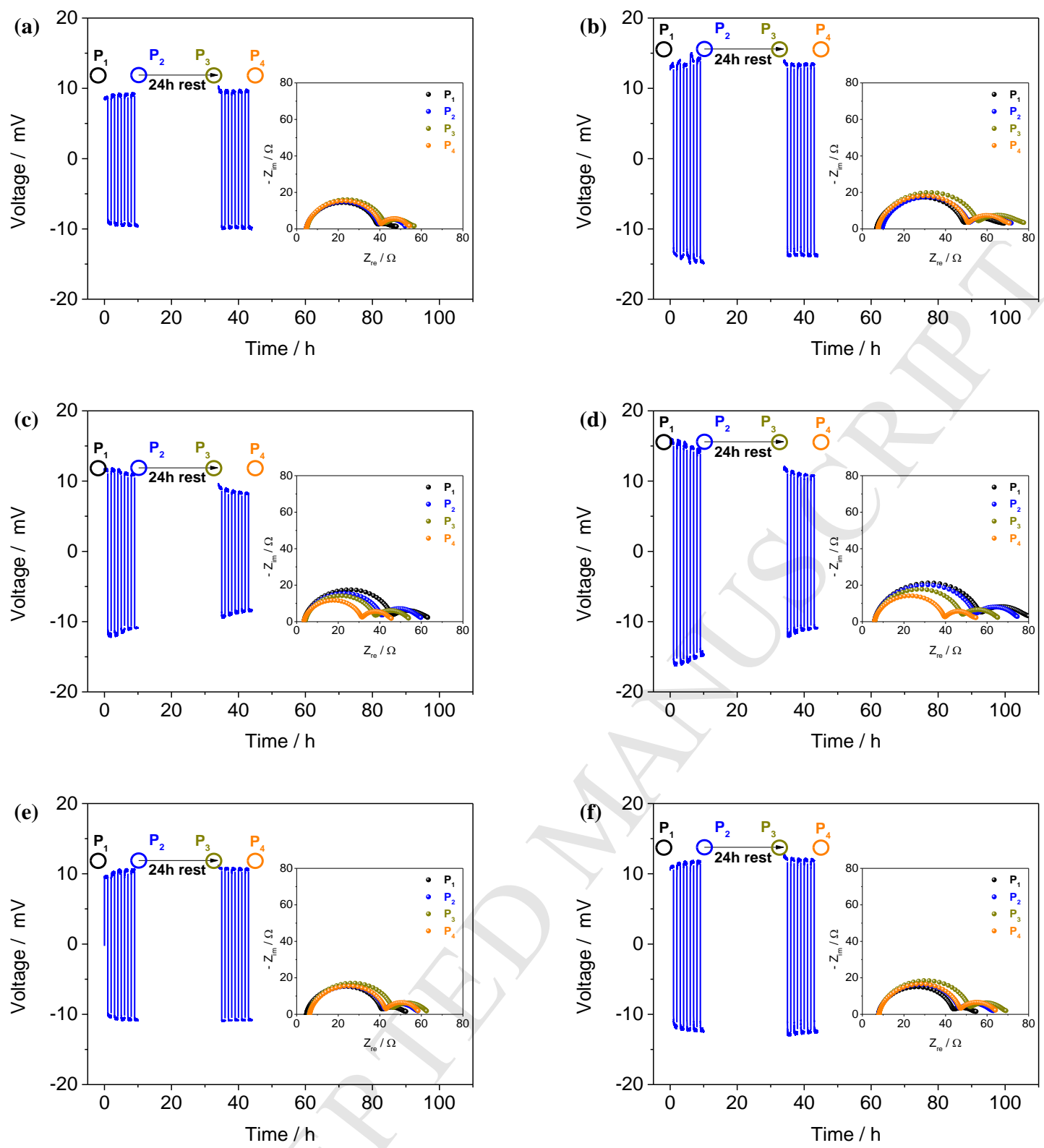

Figure 6 

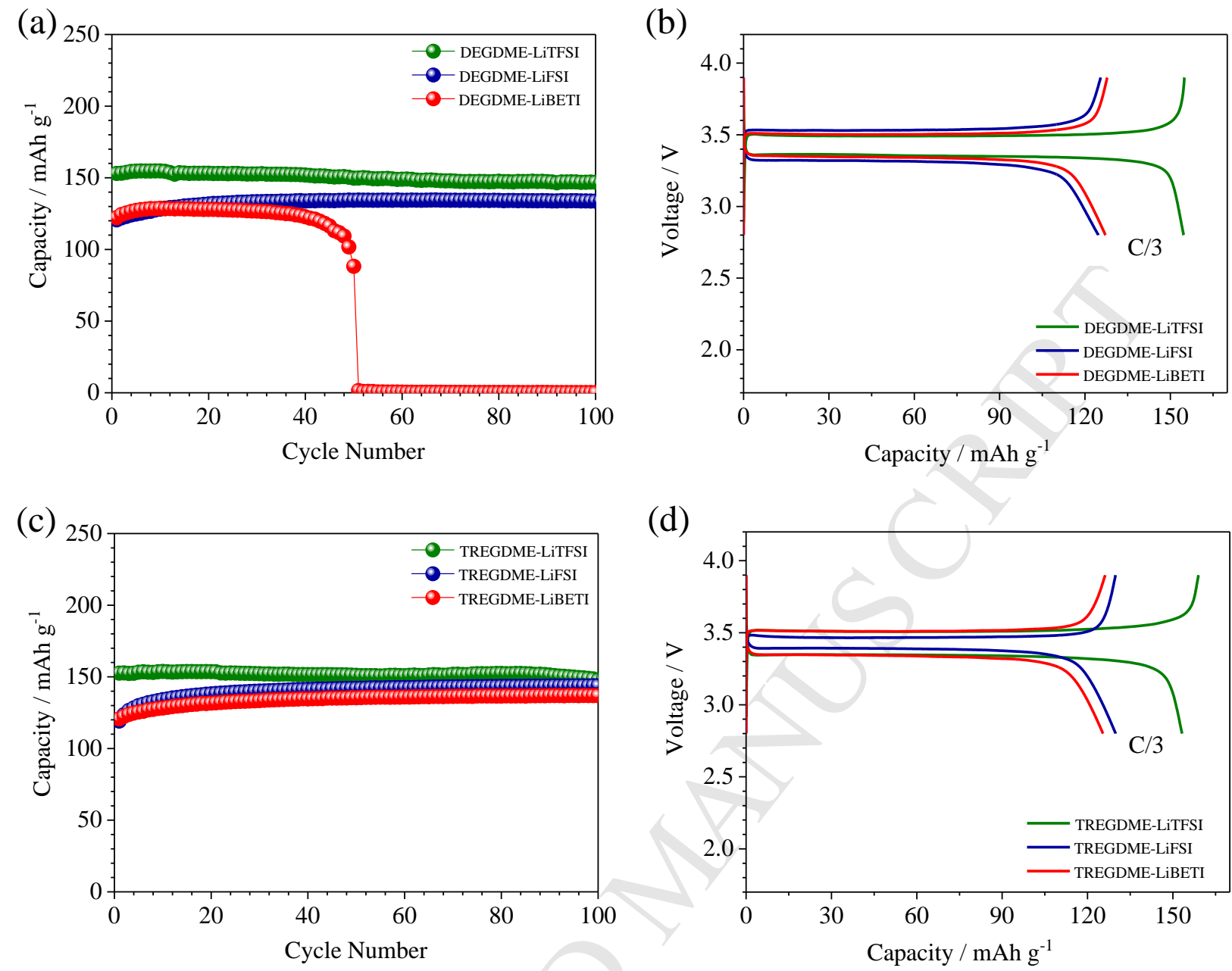

Figure 7 